\title{
Extraction and Fractionation of Whole Black Seed Plantain (Plantago rugelii Decne) for in-vitro Antioxidant, Antibacterial and Phytochemical Screening
}

\author{
*11OGBIKO, C; ${ }^{2}$ EBOKA, CJ; ${ }^{1}$ TAMBUWAL, AD \\ ${ }^{I}$ Department of Pure and Applied Chemistry, Faculty of Science, Usmanu Danfodiyo University Sokoto, Sokoto State, Nigeria. \\ *Email: cyrilogbiko@gmail.com; cyril.ogbiko@udusok.edu.ng \\ ${ }^{2}$ Department of Pharmaceutical Chemistry, Faculty of Pharmacy, University of Benin, Benin City, Nigeria
}

\begin{abstract}
This study was designed to explore new antioxidant and antimicrobial agents from the methanol whole plant crude extract and fractions of Plantago rugelii. The methanol extract and its fractions were prepared and screened for its phytochemical composition, in-vitro antioxidant potential and challenged with common pathogenic microorganisms for its antimicrobial activities using standard procedures. The phytochemical analysis revealed the presence of various pharmaceutically active secondary metabolites like alkaloids, phenolic, flavonoids, carbohydrates, glycosides, sterols, etc. In the DPPH assay, the aqueous methanol fraction was found to be the most effective among all the fractions in comparison to the ascorbic acid standard. Using the zone of inhibition as inhibitory parameter, the crude methanol extract exhibited the best antibacterial activity when challenged against all the clinical isolates except Klebsiella pneumoniae. The aqueous methanol extract exhibited the best percentage fungal inhibition when compared to other fractions. The standard drugs ciprofloxacin and fluconazole exhibited a near $100 \%$ activity except with Proteus vulgaris where the crude methanol extract has a higher value.This research holds promise for the exploration of various potentially active secondary metabolites which would help in developing pharmaceuticals, especially antioxidant and antimicrobial drugs. The isolation and characterization of the exact metabolites responsible for these activities is therefore recommended.
\end{abstract}

\section{DOI: https://dx.doi.org/10.4314/jasem.v22i5.1}

Copyright: Copyright (C) 2018 Ogbiko et al. This is an open access article distributed under the Creative Commons Attribution License (CCL), which permits unrestricted use, distribution, and reproduction in any medium, provided the original work is properly cited.

Dates: Received: 07 August 2017; Revised: 13 December: 2017; Accepted: 22 January 2018

Keywords: Plantago rugelii, Antioxidant, Free Radicals, Antimicrobial

There is accumulated evidence from researches to demonstrate the promising potentials of medicinal plants as presently used in various traditional, complementary and alternate systems of treatment of human diseases (Dahanukar et al., 2000; Cowan, 1999). Medicinal plants are useful for healing and as well for curing human diseases because of the presence of phytochemical constituents (Fabricant and Farnsworth, 2001). Phytochemicals are naturally occurring compounds in medicinal plants which offer defense mechanism and protection from various diseases (Motaleb, 2011). Coupled with the significant increase in the incidence of side effects and the resistance that pathogenic microorganisms build against several antibiotics, research on medicinal plants has attracted a lot of attentions globally (Finch, 1998; Iwu et al., 1999; Kunin, 1993). Most of the medicinal plants holding active secondary metabolites with high antioxidant property which are playing important role in the prevention of various diseases (Lobo et al., 2010). Natural antioxidants from plant sources are potent and safe due to their harmless nature hence the upsurge in recent scientific search for potential antioxidant with reduced side effects and economic viability (Auudy et al., 2003).

Species of the genus Plantago (commonly known as plantain) have been used extensively for medicinal purposes (Blumenthal et al., 2000). Plantago rugelii (Plantaginaceae) is found all over the world including Asia, Australia, New Zealand, Africa and Europe. The leaves of $P$. rugelii have been utilized as topical for wounds, bites, stings, bronchial infection, hepatitis, and jaundice among others. Its seeds have been established to be used in treating urinary infections (David, 2006). Hence the attempt is been made in this study to examine the various phytochemical constituents, antimicrobial and antioxidant efficacy of the various solvent extracts of $P$. rugelii.

\section{MATERIALS AND METHODS}

Plant materials collection, preparation and identification: Fresh $P$. rugelii whole plants comprising the root, stem and leaves were collected in June, 2012 from a forest in Owerre Olubor in Ika North East Local Government of Delta State Nigeria. The whole plants were washed with water to remove

*Email: logbiko@gmail.com; cyril.ogbiko@udusok.edu.ng 
earthy impurities, identified and authenticated at the forest research institute of Nigeria (FRIN), Ibadan where a herbarium specimen was deposited and a voucher number 109775 issued. They were then air dried for three weeks, powdered with the aid of a clean mechanical grinder and stored in an air tight glass container until use

Chemicals: Methanol (Merck India), 1,1-Diphenyl-2picrylhydrazyl (Merck India), acetone (Merck India), chloroform (Sigma Aldrich), ethyl acetate (Sigma Aldrich), petroleum ether (Sigma Aldrich) and other chemicals and reagents were all of analytical grade.

Extraction and Fractionation:The powdered whole plant comprising the root, stem and leaves was macerated with analytical grade methanol for 72 hours. The methanol was removed and residue immersed further in methanol for a further five days. Thereafter, the methanol was decanted and filtered with Whatman filter paper. The filtrate was concentrated under reduced pressure at $45^{\circ} \mathrm{C}$ in rotator evaporator (Stuart RE 300) and dried at room temperature to constant weight. This was crude methanol whole plant extract (CME). The CME was subjected to solvent-solvent extraction for four fractions, namely, pet ether, chloroform, ethyl acetate and aqueous fractions to obtain the PEF, CHF, EAF and AMF respectively. All the fractions were concentrated in the rotary evaporator at $45^{\circ} \mathrm{C}$ and stored at $4^{\circ} \mathrm{C}$ till use.

Phytochemical analysis: Simple chemical tests to detect the presence of carbohydrates, proteins and secondary metabolites in the CME, PEF, CF, EAF and AMF fractions were done in accordance with standard methods (Stahl, 1973; Sofowora, 1982; Trease and Evans, 1978).

Antioxidant assay using 2,2-diphenyl-1picrylhydrazyl (DPPH):The DPPH assay has been largely used as a quick, reliable and reproducible parameters to search for the in-vitro antioxidant parameter of pure compounds as well as plant extracts. The scavenging effect of crude methanol extract and fractions of $P$. rugelii whole plant on DPPH radical was estimated with method described by Jain et al., 2008. A solution of $0.1 \mathrm{mM}$ DPPH in methanol was prepared, and $1.0 \mathrm{~mL}$ of this solution was mixed with $3.0 \mathrm{~mL}$ of extract in methanol containing $0.01-0.2$ $\mathrm{mg} / \mathrm{mL}$ of the extract. The reaction mixture was vortexed thoroughly and left in the dark at room temperature for 30 minutes. The absorbance of the mixture was measured spectrophotometrically at 517 $\mathrm{nm}$. Ascorbic acid was used as reference standard. The ability to scavenge DPPH radical was calculated by the following equation:

$$
\operatorname{DPPH} \operatorname{RSA}(\%)=\frac{\mathrm{A} 0-\mathrm{A} 1}{\mathrm{~A} 0} \times 100(1)
$$

Where RSA = radical scavenging activity; $\mathrm{A}_{0}$ was the absorbance of DPPH radical + methanol, $\mathrm{A}_{1}$ was the absorbance of DPPHradical + sample extract /standard. Concentrations of 10, 25, 50, 100 and $200 \mathrm{ug} / \mathrm{ml}$ of the crude extracts and its different fractions are used for the study (Jain et al., 2008). The values are presented as the means of triplicate analysis.

Collection of the Microorganisms: The hospital strains were collected from different specimens (vaginal, urine, scars, etc.) of patients referred to the Medical Microbiology Department, University of Benin Teaching Hospital, Benin City Edo State Nigeria. These bacterial isolates were Staphylococcus aureus, Escherichia coli, Proteus vulgaris, Pseudomonas aeruginosa, Klebsiella pneumoniae and Enterobacter aerogenes while the fungal isolates are Aspergillus niger and Candida albicans

Confirmation of test organisms: Biochemical analysis methods as described by MacFaddin (MacFaddin, 2000), Fobres and Sham 2002 and Leboffe and Pierce, 2002 were carried out on each of the test bacteria isolates for confirmation. The Bergey's Manual of Systematic Bacteriology (Sneath et al., 1986) was used for species authentication. The fungi isolates of Aspergillus niger and Candida albicanswas identified via macroscopic and microscopic observations as well as germ tube test and chlamydospore production on cornmeal agar fortified with Tween 80 polysorbate.

Preparation of organisms: Preparation of standard bacterial suspensions:The average number of viable, bacterial organisms per $\mathrm{ml}$ of the stock suspensions was determined by means of the surface viable counting technique (Miles and Misra, 1938). About $10^{8}-10^{9}$ colony forming units per $\mathrm{ml}$ were used. Each time, a fresh stock suspension was prepared; the experimental conditions were maintained constant so that suspensions with very close viable counts would be obtained (Sajid et al., 2013). These bacterial suspensions were challenged with the dilutions of $25 \mathrm{mg} / \mathrm{mL}, 50 \mathrm{mg} / \mathrm{mL}, 75 \mathrm{mg} / \mathrm{mL}, 100 \mathrm{mg} / \mathrm{mL}$, and $125 \mathrm{mg} / \mathrm{mL}$ of the CME, PEF, CHF, EAF and AMF fractions respectively. Ciprofloxacin at $20 \mathrm{mcg} / \mathrm{mL}$ was used as the positive control.

Preparation of standard fungal suspensions: The fungal cultures Aspergillus niger and Candida albicans were maintained on Saboraud Dextrose Agar, 
incubated at $25^{\circ} \mathrm{C}$ for 4 days. The fungal growth was harvested and washed with sterile normal saline and finally suspended in $(100 \mathrm{ml})$ of sterile normal saline and the suspension was maintained for further use (Sajid et al., 2013). These fungal suspensions were with the dilutions of $25 \mathrm{mg} / \mathrm{mL}, 50 \mathrm{mg} / \mathrm{mL}, 75$ $\mathrm{mg} / \mathrm{mL}, 100 \mathrm{mg} / \mathrm{mL}$, and $125 \mathrm{mg} / \mathrm{mL}$ of the CME, PEF, CHF, EAF and AMF fractions respectively. Fluconazole at $100 \mathrm{mcg} / \mathrm{mL}$ was used as the positive control.

Antimicrobial activity: Testing for antibacterial activity: The agar well diffusion method was used (Kavanagh, 1972) to assess the antibacterial activity of the prepared extracts. $0.6 \mathrm{ml}$ of standardized bacterial stock suspensions of $10^{8}-10^{9}$ colony forming units per $\mathrm{ml}$ was thoroughly mixed with $60 \mathrm{ml}$ of sterile nutrient agar. $20 \mathrm{ml}$ of the inoculated nutrient agar were distributed into sterile Petri dishes. The agar was left to set and in each of these plates, 4 cups, $10 \mathrm{~mm}$ in diameter, were cut using a sterile cork borer No. 4 and the agar discs were removed. Alternate cups were filled with $0.1 \mathrm{ml}$ of each extracts prepared in dimethyl sulfoxixe (DMSO) using micropipette and allowed to diffuse at room temperature fortwo hours.

The plates were then incubated in the upright position at $37^{\circ} \mathrm{C}$ for 18 hours. Three replicates were carried out for each extract against each of the test organism. The antibacterial activity of samples was compared with the standard drug ciprofloxacin $(20 \mu \mathrm{g} / \mathrm{mL})$ in DMSO. The antibacterial activity of samples compared with the standard drug ciprofloxacin was measured using the zone of inhibition as the inhibitory parameter (Sajid et al., 2013).

Testing for anti-fungal activity:The same method as for bacteria was followed. Instead of nutrient agar media, yeast and mould extract agar was used. The inoculated medium was incubated at $25^{\circ} \mathrm{C}$ for two days for Candida albicans and three days for Aspergillus niger. This was carried out in triplicate for each fungus. Antibiotic susceptibility was carried out on DMSO and the test drug (fluconazole) to serve as negative and positive control respectively (Sajid et al.., 2013). The percent growth inhibition was calculated with reference to the negative control by applying the formula:

$$
\% \text { FI }=\frac{\text { LGn-LGs }}{\text { LGn }} \times 100
$$

Where FI = Fungal Inhibition, LGn and LGs are the linear growth of the negative control and sample respectively (Hameed, 2014).
Statistical Analysis: Obtained data were analyzed using Statistical Package for Social Sciences (SPSS 17.0, Chicago, IL) at 0.05 level of significance. Results were presented as mean and standard deviation (Mean \pm SD) for triplicate determination. The statistical significance between the control and each of the treated groups was determined by the Fischer's least significant difference post hoc test after one-way ANOVA. The level of significance was set at $P<0.05$.

\section{RESULTS AND DISCUSSION}

Percentage yield of the crude methanol extract and fractions: The percentage yield of the methanol plant extract was $4.73 \%$, while the percentage yield of the petroleum ether, chloroform, ethyl acetate and aqueous methanol fractions with respect to the crude methanol whole plant extract were $25.51 \%, 2.83 \%$, $1.34 \%$ and $69.68 \%$ respectively.

Phytochemical Screening: The preliminary phytochemical screening of the fractions of $P$. rugelii showed the presence of important secondary metabolites which is presented in Table 1. The presence of these phytochemicals is responsible for the diverse tradomedical application of the plant. This finding is in agreement with the findings of Ekharo and Eboka, 2011 who reported the presence of these phytochemicals in the crude methanol whole plant of $P$. rugelii. The DPPH assay method is based on the reduction of DPPH in alcoholic solution in the presence of a hydrogen-donating antioxidant due to the formation of the non-radical form, DPPH-H in the reaction (Singleton and Orthofer, 1999). DPPH is usually used as a reagent to evaluate free radical scavenging activity of antioxidants because it is a stable free radical which accepts an electron or hydrogen radical to become a stable diamagnetic molecule. The crude methanol whole plant extract and its fractions showed a remarkable and concentration dependent increase in the radical scavenging. The free radical scavenging activity of the methanol whole plant extract and its fractions is in the order: AMF > $\mathrm{EAF}>\mathrm{CHF}>\mathrm{PEF}>\mathrm{CME}$ indicating that the aqueous methanol fraction has the highest scavenging effect. Antioxidant activity of the plant is related to the presence of phenolic compounds such as flavonoids, phenolic acids and tannins. Polyphenols play an important role in the stabilization of lipid oxidation and may contribute directly to antioxidative action. It is suggested that polyphenolic compounds have inhibitory effects on mutagenesis and carcinogenesis (Gursoy et al., 2009). Flavonoids are widely distributed group of plant phenolic compounds responsible for the antioxidant activity of the plants. 
Table 1. Preliminary phytochemical screening of the fractions of $P$. rugelii

\begin{tabular}{|c|c|c|c|c|c|}
\hline \multirow{2}{*}{$\begin{array}{l}\text { Phytochemica } \\
\text { Is }\end{array}$} & \multirow[t]{2}{*}{ Tests } & \multicolumn{4}{|c|}{ Fractions of $P$. rugelii } \\
\hline & & PEF & CHF & EAF & AMF \\
\hline \multirow[t]{4}{*}{ Alkaloids } & Mayer's & + & + & + & + \\
\hline & Dragendroff's & + & + & + & + \\
\hline & Wagner s & + & + & + & + \\
\hline & Hagers & + & + & + & + \\
\hline \multirow{3}{*}{$\begin{array}{l}\text { Carbohydrate/ } \\
\text { Reducing } \\
\text { sugars }\end{array}$} & Molisch's & - & - & + & + \\
\hline & Fehling's & - & - & + & + \\
\hline & Benedicts & - & - & + & + \\
\hline $\begin{array}{l}\text { Cardiac } \\
\text { glycoside }\end{array}$ & $\begin{array}{l}\text { Keller } \\
\text { Kiliani's }\end{array}$ & - & - & + & + \\
\hline Saponins & Frothing & + & + & - & - \\
\hline \multirow[t]{2}{*}{ Tannins } & Ferric chloride & - & - & - & - \\
\hline & Gelatin & - & - & - & - \\
\hline \multirow[t]{2}{*}{ Phytosterols } & Salkowski & + & - & - & - \\
\hline & $\begin{array}{l}\text { Liebermann- } \\
\text { Burchard }\end{array}$ & + & - & - & - \\
\hline \multirow[t]{2}{*}{ Triterpenes } & Salkowski & + & - & - & - \\
\hline & $\begin{array}{l}\text { Liebermann- } \\
\text { Burchard }\end{array}$ & + & - & - & - \\
\hline \multirow[t]{2}{*}{ Proteins } & Biuret & - & - & - & - \\
\hline & Ninhydrin & - & - & - & - \\
\hline \multirow{2}{*}{$\begin{array}{l}\text { Phenolic } \\
\text { compounds }\end{array}$} & Ferric chloride & + & + & + & + \\
\hline & $\begin{array}{l}\text { FolinCiocalteu } \\
\text { 's }\end{array}$ & + & + & + & + \\
\hline \multirow[t]{3}{*}{ Flavonoids } & Shinado Test & + & - & + & + \\
\hline & Ferric chloride & + & - & + & + \\
\hline & Lead acetate & + & - & + & + \\
\hline Anthraquinone & Borntrager's & - & - & - & - \\
\hline $\mathrm{s}$ & Ferric chloride & - & - & - & - \\
\hline
\end{tabular}

DPPH radical scavenging assay: The radical scavenging property of the crude extract and fractions of $P$. rugelii is shown in Figure 1

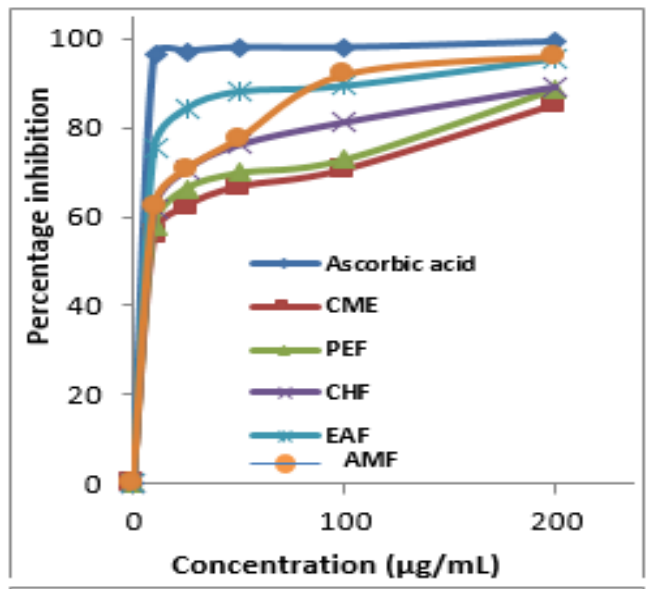

Figure 1. DPPH radical scavenging activity of crude $P$. rugelii extract, its fractions and the synthetic antioxidant (ascorbic acid) at different concentrations. Each point is a mean from triplicate measurement.

It has been proven to display a wide range of pharmacological and biochemical activities including radical scavenging properties (Prasad et al., 2009). These findings support earlier reports that plant metabolites like phenolic contents, tannins and flavonoids possesses antioxidant activity (Rice-Evans et al., 1997). These phytochemical except tannins were reported to be present in the extract (Table 1). The result showed that the standard antioxidant (ascorbic acid) had stronger activity than the tested extracts, probably because the former contain more purified compounds than the latter.

\section{Antibacterial and Antifungal activity}

The result presented in Figure 2 and 3 reveals the in vitro susceptibility of the bacteria isolates and the percentage fungal inhibition (at $125 \mathrm{mg} / \mathrm{mL}$ ) of the whole plant extract and fractions of $P$. rugelii in comparism to ciprofloxacin $(20 \mu \mathrm{g} / \mathrm{mL})$ and fluconazole standard $(100 \mu \mathrm{g} / \mathrm{mL})$ respectively.

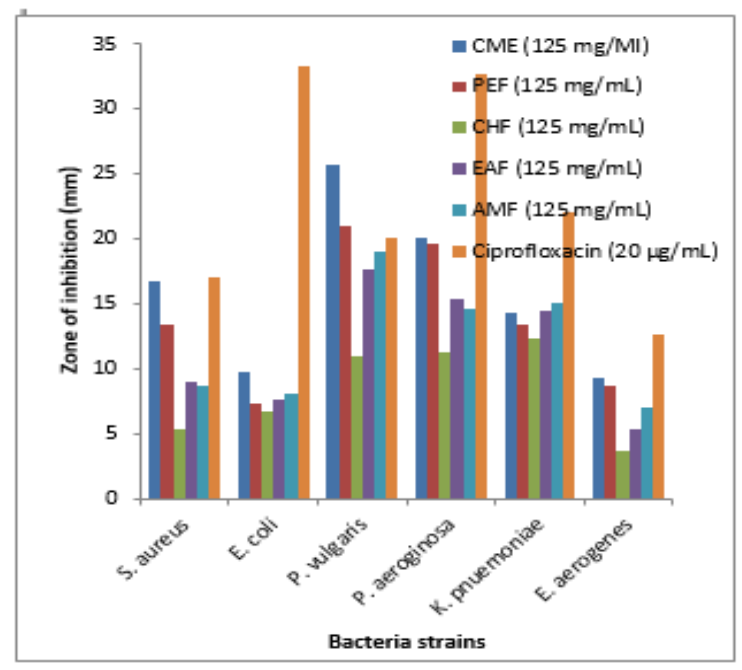

Figure 2: Antimicrobial activity (zone of inhibition) of $P$. rugelii crude extract and fractions against various human pathogens.

Natural antimicrobial compounds from plants act as therapeutics that can inhibit the growth of pathogens and have been used to overcome the side effects associated with the synthetic antimicrobial agents. The crude extract and its fraction showed varying activity against the bacteria isolates investigated. While the best activity was exhibited by the CMF on $P$. vulgaris with the inhibition zone $(25.67 \pm 0.20)$, the least activity was exhibited by the CHF against $E$. aerogenes with the inhibition zone $(3.67 \pm 0.09)$. The CHF generally showed the least activity amongst the fractions. The result of the anti-fungal assay indicated 
that the CMF has the least activity against the challenged fungiwith \% inhibition of 13 and 24 while the best activity with \% inhibition of 69 and 74 was obtained for the AMF for Aspergillus niger and Candida albicans respectively. Both ciprofloxacin and fluconazole) exhibited a $100 \%$ or near $100 \%$.

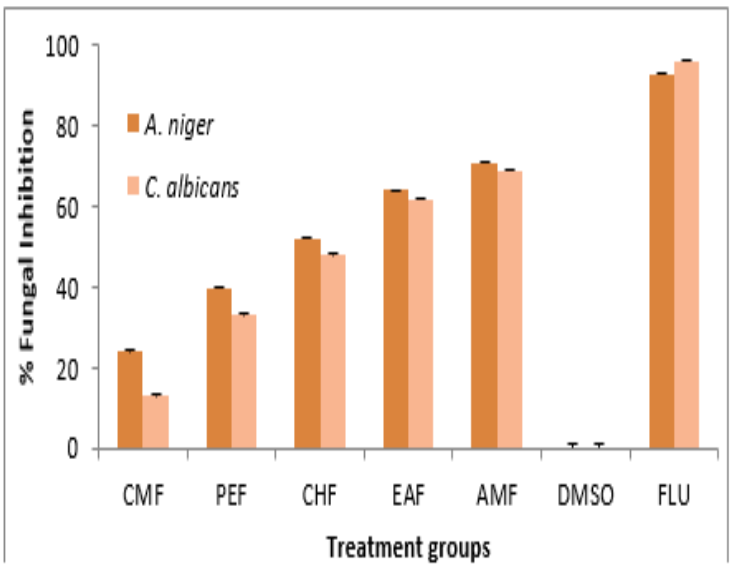

Figure 3: Comparison of the percentage fungal inhibition of $P$. rugelii crude extract, its fractions and fluconazole standard. DMSO $=$ Dimethyl sulphoxide and FLU $=$ Fluconazole . Data represent Mean \pm SD of three replicates

The antimicrobial activity recorded for the crude plant extract and its fraction is in agreement with the report of Cooper et al. (2006) was reported that the presence of more group of phytochemical diversity gives synergic effects in many biological applications. The disparity between the activities of the extracts and the standard antimicrobial drugs may be due to the mixtures of bioactive compounds present in the extracts compared to the pure compound contained in the standard antibiotics (Gatsinget al., 2010).

Conclusion: The present study summarizes that $P$. rugelii is a good source of various metabolites like steroids, flavonoids, glycosides, alkaloids and carbohydrates. The crude methanol extract and the fractions of the plant showed promising broad spectrum antimicrobial activity and radical scavenging activity comparable to standard ciprofloxacin, fluconazole and the free radical scavenging activity of ascorbic acid. The finding of this study suggests that the leaves of this plant could be a potential source of natural antioxidant. These results encourage the researchers to do further in vitro and in vivo research that will explore the role of bioactive constituents responsible for these activities as well as carry out studies at molecular level.

\section{REFERENCES}

Auudy, B; Ferreira, M; Blasina, F; Lafon, L; Arredondo, F; Dajas, F; Tripathi, PC; Seal, T; Mukherjee, B(2003). Screening of antioxidant activity of three Indian medicinal plants traditionally used for the management of neurodegenerative diseases. J. Ethnopharmacol. 84: 131-138.

Blumenthal, M; Busse, WR; Goldberg, A; Gruenwald, J; Hall, T; Riggins, CW; Rister, RS (2000). Complete German Commission E Monographs-Therapeutic guide to herbal medicines. In: Klein S; Rister, RS (ed) American Botanical Council, Integrative Medicine Communications, Boston, p.243 - 304.

Cooper, J; Niggli, U; Leifert, C (2006). Handbook of organic food safety and quality. Woodhead Publishing Limited, Abington Hall, Abington, Cambridge, CB1 6AH, England, p.34.

Cowan, MM (1999). Plant products as anti-microbial agents. Clinical microbiology reviews, 12, Edition, Morton Publishing, USA, p.45.

Dahanukar, SA; Kulkarni, RA; Rege, NN (2000). Pharmacology of Medicinal Plants and Natural Products. Indian J.Pharmacol. 32: 81- 118.

David, BL (1996). Medicine at your feet: healing plant of the Hawaiian kingdom Plantago. J. Ethnopharmacol. 76(1): 59 - 64.

Ekharo, OM; Eboka, CJ (2011). Antimicrobial activity and phytochemical studies of the methanolic whole plant extract of Plantagorugelii (Plantaginaceae). Unpublished, Department of Pharmaceutical Chemistry, Faculty of Pharmacy, University of Benin. p.57 - 60 .

Fabricant, DS; Farnsworth, NR (2001). The value of plants used in traditional medicine for drug discovery. Env. Health Perspect.109(1): 69-76.

Finch, RG (1998). Antibiotic resistance. J. Anti. Chemo. 42: 125-128.

Fobres, BD; Sham, A (2002). Weissfield. Diagnostic Microbiology. 11th Edition, Andrew Allen Press, Canada, p.56-59.

Gatsing, D; Nkeugoauapi, CFN; Nkah, BFN; Kuiate, JR; Tchouanguep, FM (2010). ChenopodiumambrosioidesLinn., an indigenous 
medicinal plant. Afr. J. Pharm. and Pharmacol. 8(8): 231-234.

Gursoy, N; Sarikurkcu, C; Cengiz, M; Solak, MH (2009). Antioxidant activities, metal contents, total phenolics and flavonoids of seven Morchellaspecies. Food Chem.Toxicol. 47: 23812388.

Hameed, S (2014). Antibacterial and Antifungal activities of the crude extract from the stem of Int. J.Pharmacol. 6: 173-182.

Iwu, MW; Duncan, AR; Okunji, CO (1999). New antimicrobials of plant origin. In: Janick J. (ed) Perspectives on New Crops and New Uses. ASHS press, Alexandria, p.457-462.

Jain, A; Soni, M; Deb, L; Jain, A; Rout, S; Gupta, V; Krishna, K (2008). Antioxidant and hepatoprotective activity of ethanolic and aqueous extracts of MomordicadioicaRoxb. leaves. J. Ethnopharmacol. 115(1): 61 - 66.

Kavanagh, F (1972). Analytical Microbiology. F. Kavanagh (ed), Vol II, Academic press, New York,p.11.

Kunin, CM (1993). Resistance to antimicrobial drugs a worldwide calamity. Ann. Int. med.12: 564-582.

Leboffe, MJ; Pierce, BE (2002). Microbiology Laboratory Theory and Application. $1^{\text {st }}$ Edition, Morton Publishers, USA, p.76-79.

Lobo, V; Patil, A; Phatak, A; Chandra, N (2010). Free radicals, antioxidants and functional foods: Impact on human health. Pharmacog. Rev.4(8): 118.

MacFaddin, JF (2000). Biochemical Tests for Identification of Medical Bacteria. 3rd Edition. ASM Press, Washington, DC, p.87.

Miles, AA; Misra, SS (1938). Estimation of bacterial power of blood. J.Hyg. 38: 732-749.
Motaleb, MA (2011).Selected medicinal plants of Chittagong hill tracts. International union of conservation of nature and natural resources. P.13.

Prasad, KN; Yang, B; Dong, X; Jiang, G; Zhang, H; Xie, H (2009). Flavonoid contents and antioxidant activities from Cinnamomumspecies. Innov. Food Sci.Emerg. Technol. 10: 627-32.

Rice-Evans, CA; Miller, C; Paganga, NJ; Paganga, G (1997). Structure, antioxidant activity and relationships of flavonoids and phenolic acids. Free rad. Bio. Med.20: 933-956.

Sajid, N; Nizam, B; Sajid, B; Tamina, N; Yasser, MSSA (2013). Invitroantimicrobial, antitumor, cytotoxic activities of the methanolic activities and its fractions of AcantolimonLosgiscapum. Int. J.Phytopharmacol. 4(3): 179 - 183.

Singleton, VL; Orthofer, R (1999). Analysis of total and other oxidation substrates and antioxidants by means of Folin-Ciocalteru reagent. Methods Enzymol. 299: 152-178.

Sneath, PHA; Mair, NS; Sharpe, ME; Holt, JG (1986). Bergey's Manual of Systematic Bacteriology. Vol. 2, Williams and Wilkins, Philadephia, p.98.

Sofowora, A (1982). Screening plants for bioactive agents. In: medicinal plants and traditional medicine in Africa.Spectrum Books Ltd, Ibadan, p.289.

Stalh, E (1973). Drug analysis by chromatography and microscopy. A Practical Supplement to Pharmacopoeias. (1st ed.). Ann Arbor, Michigan, p.219 - 224.

Trease, EA; Evans, WC (1978). Pharmacognosy. (11th ed.). Churchill Livingstone Harcourt Health Service, London, p.60 - 75. 